\title{
Correction to: Effect of varying biogas mass flow rate on performance and emission characteristics of a diesel engine fuelled with blends of $n$-butanol and diesel
}

\author{
Geetesh Goga ${ }^{1} \cdot$ Bhupendra Singh Chauhan ${ }^{2} \cdot$ Sunil Kumar Mahla ${ }^{3} \cdot$ Amit Dhir $^{4} \cdot$ Haeng Muk Cho $^{5}$
}

Published online: 23 January 2020

○) Akadémiai Kiadó, Budapest, Hungary 2020

\section{Correction to: Journal of Thermal Analysis and Calorimetry https://doi.org/10.1007/s10973-019-09055-1}

In the original publication of the article, Figs. 6 and 7 were published incorrectly without test fuel D80/nb20+BG $(0.5$ $\mathrm{kg} \mathrm{h}^{-1}$ ). The corrected Figs. 6 and 7 along with corrected test values are given in this correction.

As shown in the Fig. 6, the peak cylinder gas pressure for conventional diesel was around $53 \mathrm{bar}$, and for dual fuel operational mode, it was 53.56, 54.05, 54.51, 54.74, 55.88 and 56.89 bar for D90/nb10 + BG $0.5 \mathrm{~kg} \mathrm{~h}^{-1}$, D90/nb10 + BG $1.2 \mathrm{~kg} \mathrm{~h}^{-1}, \mathrm{D} 90 / \mathrm{nb} 10+\mathrm{BG} 2 \mathrm{~kg} \mathrm{~h}^{-1}, \mathrm{D} 80 / \mathrm{nb} 20+\mathrm{BG}$ $0.5 \mathrm{~kg} \mathrm{~h}^{-1}, \mathrm{D} 80 / \mathrm{nb} 20+\mathrm{BG} 1.2 \mathrm{~kg} \mathrm{~h}^{-1}$ and D80/nb20 +BG $2 \mathrm{~kg} \mathrm{~h}^{-1}$, respectively.

As illustrated in Fig. 7, the maximum net heat release rate for conventional diesel was estimated to be $42.25 \mathrm{~J} /{ }^{\circ} \mathrm{CA}$ when compared to 43.09, 44.16, 45.28, 45.67, 46.48 and $47.88 \mathrm{~J}$ ${ }^{\circ} \mathrm{CA}^{-1}$ for D90nb10 + BG $0.5 \mathrm{~kg} \mathrm{~h}^{-1}$, D90nb10 + BG $1.2 \mathrm{~kg}$ $\mathrm{h}^{-1}, \mathrm{D} 90 \mathrm{nb} 10+\mathrm{BG} 2 \mathrm{~kg} \mathrm{~h}^{-1}, \mathrm{D} 80 / \mathrm{nb} 20+\mathrm{BG} 0.5 \mathrm{~kg} \mathrm{~h}^{-1}$,

The original article can be found online at https://doi.org/10.1007/ s10973-019-09055-1.

Sunil Kumar Mahla mahla.sunil@gmail.com

$\triangle$ Amit Dhir amit.dhir@thapar.edu

1 School of Mechanical Engineering, Lovely Professional University, Phagwara, Punjab, India

2 Department of Mechanical Engineering, Meerut Institute of Engineering and Technology, Meerut, Uttar Pradesh, India

3 Department of Mechanical Engineering, IKG Punjab Technical University, Kapurthala, Punjab, India

4 School of Energy and Environment, Thapar Institute of Engineering and Technology, Patiala, India

5 Department of Mechanical Engineering, Kongju National University, Cheonan, South Korea

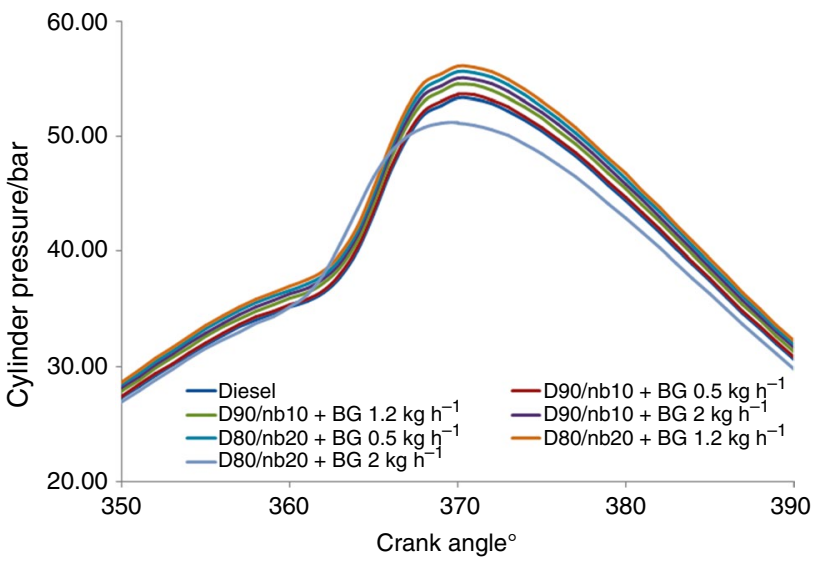

Fig. 6 Variation in cylinder gas pressure with crank angle at full engine load

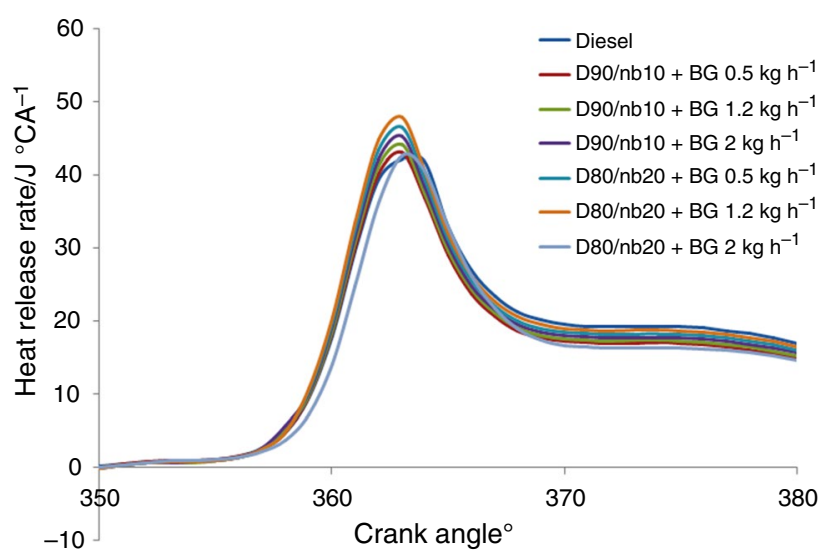

Fig. 7 Variation in NHRR with crank angle at full engine load

D80/nb20 + BG $1.2 \mathrm{~kg} \mathrm{~h}^{-1}$ and D80/nb20 + BG $2 \mathrm{~kg} \mathrm{~h}^{-1}$, respectively, at full engine operating load.

Publisher's Note Springer Nature remains neutral with regard to jurisdictional claims in published maps and institutional affiliations. 